\title{
Open Access: An Old Tradition and a New Technology...
}

Jean-Claude Guédon

Université de Montréal

Open Access $(\mathrm{OA})$ is no longer a laughing matter; neither can it be ignored. Benign neglect is no longer a viable option either. It is a goal that many government research funding agencies have examined and adopted. So have many private foundations. Libraries have been on the front lines of the OA debate, supporting OA objectives from the very beginning. By the late 1980's scholars and scientists had also begun to see the possibilities that the Internet and personal computers could achieve when combined in the right way: an old tradition - the Republic of Letters, and a new technology - networked computers, had begun to merge, thus creating a new context for the production, validation, storage, dissemination and reception of scholarly documents.

Publishers certainly saw the new technology, but were not so sanguine about an open Republic of Letters. The issue for them was to move to the digital world while maintaining control over their material. Slashing production costs also proved very appealing while getting rid of a few bothersome copyright provisions was also on their agenda. The latter objective they achieved by forsaking outright sales in favour of licensing, exactly as the software industry had done earlier².

By contrast, most research and academic administrators missed most of what made up the digital wave, and so did most bureaucrats in education ministries everywhere. Why this is so would make for a fascinating story, but it would take us well beyond this small introduction. It is enough to say here that the right hand of these institutions did not always know what the left hand was doing. For example, evaluation procedures for promotion and tenure, because they tend to rely on the safe symbolic value of prestigious titles selected by the Web of Science, contribute to the reinforcement of an inelastic market for scholarly journals. The presence of an inelastic market for journals does more to explain the rapid rise in subscription/licensing prices than any other factor. Meanwhile, libraries struggled to pay the bills out of their institutional budgets.

OA started with a small number of dispersed individuals pursuing a variety of objectives. It came together and formed the beginning of a movement when the Open Society Institute (OSI), a private foundation supported by the financier George Soros, invited a number of individuals to Budapest at the end of 2000. of the eighteen people that met in Budapest, Canada was clearly over-repre- 
sented with three representatives: Stevan Harnad (who hails from Montreal and was soon to take up a research chair at Université du Québec à Montréal) played a crucial role in defending what would become the self-archiving or "Green Road" strategy. Leslie Chan, from the University of Toronto at Scarborough, had considerable hands-on experience with scientific journals publishing in the Third World. Somehow, I was also invited. As is well known, the Budapest meeting gave rise to the Budapest Open Access Initiative (BOAI) that came out on Saint Valentine's day - what a symbol! - in 2001. That is when the OA movement began to cohere and received significant financial support from OSI.

From 2001 to the present, OA has constantly grown and evolved to become, as was stated at the outset, something that could no longer be ignored or laughed at. A few telling examples will provide the needed sense of scale surrounding this movement. The Directory of Open Access Journals (DOAJ), housed at the University of Lund in Sweden points now to just under 4700 peer-reviewed titles from all over the world and in all disciplines. Meanwhile people can self-archive their articles in around 1600 repositories, throughout the world. A protocol, OAI-PMH, allows using the 1600 repositories with the help of network tools such as OAISTER. Even more tellingly, large trans-national commercial publishers such as Springer have bought OA commercial publishers such as Biomed Central. The largest of all the commercial publishers, Reed-Elsevier, allows the self-archiving of some version of refereed articles published in their journals so long as it is not the the publisher's "Pdf." The probable reason for this surprising show of flexibility is the concern that scientists might be alienated by frontal resistance, and the calculation that, when all is said and done, OA has not proved capable of threatening their revenue stream in a significant manner. The Public Library of Science has also demonstrated that, with OA publishing, a journal could be raised to a very high level of visibility and prestige in three or four years, while traditional approaches based on subscriptions require at least twice as much time. Finally, numerous studies have shown that articles published in Open Access tend to be read and cited more, thus helping a scholar's career to advance more rapidly. In my own case, OA publishing has led to increased readership through translations: repeatedly, colleagues in foreign countries have spotted, translated and published some of my papers in a variety of languages, including Italian, Arabic and Catalan. In short, $\mathrm{OA}$ is a game changer at all levels.

The articles that follow cover many of these issues. They can be divided relatively easily between three categories: Canadian experience with OA, foreign experience with $\mathrm{OA}$, and conceptual analysis of OA.

Canada saw a good deal of individual initiatives emerge quickly. The institutional response, however, has been slower, and, in some quarters, resistance has been expressed. Academic presses, because they are fragile, generally found the objective appealing but feared for the sustainability of their operations. Some library organizations conceived of themselves as mainly procurement agencies and, as a result, expressed fear of alienating some of their powerful material pur- 
veyors if they supported OA too openly or too vigorously. Some organizations, such as Érudit and Synergies, have emerged to help Canadian journals move on-line, but they have placed the OA issue on the back burner. Their ambivalent attitude to $\mathrm{OA}$ is well marked by the fact that a submitted abstract from one of these organizations never materialized into an article. A similar fate awaited another abstract that had come from a French e-publishing project.

Despite these lacunae, these texts provide an interesting analysis of the important role that Canadian libraries played for OA (Richard \&t alii). Another interesting study examines the issue of e-publishing and $\mathrm{OA}$ in Canada from the perspective of "disruptive technologies," thus offering an important conceptual handle on these two related facets of digitization (Anderson \& alii). This article also provides important insights into the difficulties met by e-publishing pioneers when they sought official and institutional recognition, and financial support.

Shifting ground to a conceptual and discipline-based study, Patrick Tomlin provides us with fascinating insights about the peculiarities of OA in humanistic studies, particularly in art history where copyright as applied to images creates a great many difficulties for scholars, teachers and students. This study is particularly welcome because OA debates have tended to centre around scientific journals, treating them as if all scientific disciplines behaved more or less in the same way. By focusing on a humanity discipline that involves both textual and visual elements, and by addressing the complex issue of scholarly monographs, Patrick Tomlin takes us on an original path that usefully complements previous OA studies.

The last two papers also break new ground for the OA debates by placing us squarely within Third-World situations. The paper by Metcalfe, Esseh, and Willinsky does have a foot in Canadian matters since it deals with the Acacia programme that is supported by the International Development Research Centre (IDRC). It also deals with the Open Journal System (OJS) developed in Canada by John Willinsky and his team. At the same time, it initiates us into the realities of scientific publishing in Africa. The question here is whether OA is a good answer for the promotion of African science. While it is a possibility, no one should underestimate the difficulty of creating sustainable publications when governments are unstable, and when international organizations, such as the World Bank, change their policy from time to time.

$\mathrm{OA}$, particularly when viewed from the perspective of publishing (the "Gold Road"), is constantly facing the difficult question of financing. Often, this issue is couched in terms of a "business plan." But such vocabulary implicitly incorporates the thesis, or so it seems, that some market-driven private enterprise must pursue the OA agenda. This leads to a number of confusions such as OA publishing needs be "author pays," rather than "reader pays" publishing. Perhaps using terms such as stable and viable financing would help bring a more balanced perspective on 0A, especially if we keep in mind that the great majority of research everywhere comes from public funds. If publishing research results is an integral part of the life-cycle of research, why should publishing be treated 
differently from the rest of research activities? Another way to put this question is to wonder why we never seem to worry about the business plan of research.

It is precisely from this angle that Abel Packer approaches his article on SciELO. This international publishing venture covers more than 600 journal titles coming from a dozen countries and it is viable in part because governments support it in one way or another. But this important paper also incorporates another objective which should be of some interest to Canadians. Open Access is generally construed as reading and use access to the published scientific literature (i.e. literature with peer review). The papers by Metcalfe et al. and Packer show that there is another issue lurking around the "access principle" (to use John Willinsky's well-known phrase): it is access to "a place in the sun." In other words, it is not enough to be able to publish little journals in Third World countries if, in the end, they are not read or discussed by scientific centres. If this is all Third World countries can do, their better scientists will try publishing in "established" Western journals, thus condemning local journals to a secondary status. But to publish in central journals, the better scientists from poor countries will have to focus on questions and issues that are deemed "hot" or scientifically exciting in developed nations, while neglecting questions and issues of far greater use for their own countries. In the worst-case scenarios, Third-World scientists who manage to publish in so-called "central" journals may be noted by research centres in rich countries, and they may be invited to join their ranks, thus creating the conditions for the famous brain drain that has been discussed for decades. Abel Packer and his colleagues argue that countries like Brazil need to build autonomous publishing platforms which must then be promoted by every possible means, including new means such as independent metrics. In short, access to the means of significant publishing becomes the new rallying cry. The recent extension of SciELO into Africa seems to indicate that the message is being increasingly heard. As these new publishing platforms begin to compete successfully for the "best papers," but on their own terms, they may usher vast power shifts in world science. Saying that the results of science are universally valid is one thing and most people will agree with this statement; however, it is much more difficult to claim that the ways in which scientific questions are selected and become "important" are also universal. And this situation is even more obvious in the humanities and social sciences where huge imbalances characterize our knowledge (or ignorance) of various cultures. ${ }^{4}$

Open Access, as these articles show, offers a rich perspective on the hidden and not so hidden mechanisms of scientific and scholarly publication. The small collection of articles offered here provides a useful entry point into this issue, but, obviously, much more could be said and published on this topic. And it will be, in the months and years to come, even as the digital wave continues to carry us forward into a future that is as unpredictable as was the future of European societies when print emerged in their midst in the $15^{\text {th }}$ century. If you say: "may you live in interesting times!" to a Chinese, he will take it as a curse. Open access advocates, on the other hand, will take it as a promise. 


\section{NOTES}

1. This is the now famous opening line of the Budapest Open Access Initiative. Peter Suber crafted beautifully most of this important text. See http://www. soros.org/openaccess/read.shtml.

2. Reed-Elsevier began to experiment with digital documents in 1991. Their pilot project was called Tulip, not a surprising title for a Dutch company, but the "l" of Tulip stood for "Licensing". In fact "Tulip" stands for "The University LIcensing Programme".

3. Open Archive Initiative - Protocol for Metadata Harvesting. Confusion often exists between the Open Access Initiative of Budapest and the Open Archive Initiative. The latter is really about meta-data and it can be applied to closed archives.

4. On these issues, see Canagarajah, A.S., (2002). A geopolitics of academic writing. Pittsburgh: University of Pittsburgh Press. 